\title{
Response of the Zonal Mean Atmospheric Circulation to EI Niño versus Global Warming
}

\author{
JIAN LU \\ National Center for Atmospheric Research, Boulder, Colorado \\ GANG CHEN \\ Program in Atmospheres, Oceans, and Climate, Massachusetts Institute of Technology, Cambridge, Massachusetts \\ DARGAN M. W. FRIERSON \\ Department of Atmospheric Sciences, University of Washington, Seattle, Washington
}

(Manuscript received 17 August 2007, in final form 11 March 2008)

\begin{abstract}
The change in the zonal mean atmospheric circulation under global warming is studied in comparison with the response to El Niño forcing, by examining the model simulations conducted for the Fourth Assessment Report of the Intergovernmental Panel on Climate Change. In contrast to the strengthening and contraction of the Hadley cell and the equatorward shift of the tropospheric zonal jets in response to El Niño, the Hadley cell weakens and expands poleward, and the jets move poleward in a warmed climate, despite the projected "El Niño-like" enhanced warming over the equatorial central and eastern Pacific. The hydrological impacts of global warming also exhibit distinct patterns over the subtropics and midlatitudes in comparison to the El Niño.

Two feasible mechanisms are proposed for the zonal mean circulation response to global warming: 1) The increase in static stability of the subtropical and midlatitude troposphere, a robust result of the quasi-moist adiabatic adjustment to the surface warming, may stabilize the baroclinic eddy growth on the equatorward side of the storm tracks and push the eddy activity and the associated eddy-driven wind and subsidence poleward, leading to the poleward expansion of the Hadley cell and the shift of midlatitude jets; 2) the strengthening of the midlatitude wind at the upper troposphere and lower stratosphere, arguably a consequence of increases in the meridional temperature gradient near the tropopause level due to the tropospheric warming and tropopause slope, may increase the eastward propagation of the eddies emanating from the midlatitudes, and thus the subtropical region of wave breaking displaces poleward together with the eddy-driven circulation. Both mechanisms are somewhat, if not completely, distinct from those in response to the El Niño condition.
\end{abstract}

\section{Introduction}

Given that El Niño-Southern Oscillation (ENSO) is the most prominent mode of interannual variability in the earth's climate system and has profound impacts on the global climate, there is great interest as to how the tropical Pacific sea surface temperature (SST) would respond to global warming. The Fourth Assessment Report of the Intergovernmental Panel of Climate

Corresponding author address: Jian Lu, NCAR/CGD 1850, Table Mesa Dr., Boulder, CO 80305.

E-mail: jianlu@ucar.edu
Change (IPCC) summarizes the changes in tropical Pacific SST in response to global warming as the following: "models have projected that the background tropical Pacific SST change from global warming (upon which individual ENSO events occur) will be an El Niño-like pattern. ... the El Niño-like change may be attributable to the general reduction of tropical circulations due to the increased static stability in the tropics in a warmer climate." Meanwhile, there is less agreement in the IPCC models in the feature of the zonal SST gradient in the so-called El Niño-like response (e.g., Collins et al. 2005) than in the feature of the meridional SST gradient between the equator and the sub- 
tropics (Liu et al. 2005). The latter, to zero order, can be explained by the fact that the upward latent heat flux increases more efficiently over the off-equatorial region (owing to the stronger easterly wind there) than at the equator upon a presumed same change in the sea-air humidity difference.

There is a conventional wisdom in the community that tropical SST anomalies are much more efficient than midlatitude SSTs in driving midlatitude teleconnections, and possibly zonal mean circulations as well. If the enhanced El Niño-like SST dominates, it may be expected that the zonal mean atmospheric response to the global warming should be somewhat reminiscent of the response to El Niño. However, we will show in this paper that, despite the El Niño-like features in the Pacific SST response in many models, the extratropical atmospheric responses to global warming occur in a somewhat opposite fashion to the El Niño teleconnection pattern.

Observational and diagnostic analyses (Seager et al. 2003) have shown that, during an El Niño event, the tropical atmosphere warms at all longitudes, and the subtropical jets in both hemispheres strengthen on their equatorial flanks and shift toward the equator. Poleward of the tropical warming there are latitudinal belts of marked cooling, extending from the surface to the tropopause in both hemispheres. The Hadley circulation intensifies and contracts equatorward. Similar responses occur in model simulations as well. Model experiments with a diabatic heating specified in the deep tropics of an idealized dry atmospheric model (Chang 1995; Robinson 2002; Son and Lee 2005), or a SST warming confined within $15^{\circ}$ of the equator over the Indo-Pacific oceans in the National Centers for Environmental Prediction (NCEP) Global Forecast System (GFS) model (X. Quan 2007, personal communication), or a narrow equatorial SST warming in the Geophysical Fluid Dynamics Laboratory (GFDL) AM2.1 aquaplanet model, all produce consistent intensification and contraction of the Hadley cell (HC) and the associated changes in jets and atmospheric temperatures, as observed during El Niño conditions.

On the contrary, the atmospheric response to global warming is characterized by a poleward expansion of the Hadley circulation (Lu et al. 2007), a poleward shift in eddy-driven jets (Lorenz and DeWeaver 2007; Kushner et al. 2001) and midlatitude storm tracks (Yin 2005), and a weakening of the tropical atmospheric circulation (Vecchi and Soden 2007; Lu et al. 2007). Apparently, these features of change cannot be accounted for by the El Niño-like SST response or the enhanced equatorial SST warming. Here, we try to rationalize these changes in the atmospheric circulation and dis- cuss the possible mechanisms for these changes under global warming in contrast to El Niño.

First, we describe the data, analysis metrics and techniques used in this study in section 2. Sections 3 and 4 discuss the characteristics of the SST, atmospheric circulation changes, and precipitation and evaporation under global warming in comparison with the El Niño condition. The mechanisms for the variation of the HC extent and the displacement of the eddy-driven jet are the subject of focus of this study, and will be elaborated upon in section 5. Finally, we conclude with summary and discussion in section 6 .

\section{Data and analysis metrics}

Most of the analyses in this study are based on simulations with the GFDL Coupled Climate Model version 2.1 (CM2.1). The detailed formulation of CM2.1 has been documented by Delworth et al. (2006). The atmospheric component of CM2.1, AM2.1, uses a finitevolume advection scheme and has approximately the resolution of $2^{\circ}$ latitude $\times 2.5^{\circ}$ longitude with 24 levels in the vertical. The ocean component of CM2.1 is referred to as OM3.1, which is based on the Modular Ocean Model code (MOM4; Griffies et al. 2003).

CM2.1 can reasonably simulate the periodicity and the spatial pattern of ENSO variability, except that the amplitude of the SST variations over the Niño regions are about twice as large as observed. Like other models in the community, CM2.1 also suffers some common biases in the tropical Pacific climate, such as a cold SST bias along the equator and a westward extension of the trade winds relative to observations (Wittenberg et al. 2006). Nevertheless, the teleconnection pattern and the zonal mean atmospheric signature of ENSO is very comparable to observations.

The simulation of the A2 scenario, a high-emission scenario (the $\mathrm{CO}_{2}$ concentration reaches $800 \mathrm{ppm}$ at the end of the twenty-first century), will be the focus of the analysis in this study. To facilitate a comparison between ENSO and global warming, first the simulated time series from 2001-2100 are detrended and sorted into two groups, one for years when the cold tongue index (CTI; SST averaged between $6^{\circ} \mathrm{S}$ and $6^{\circ} \mathrm{N}, 180^{\circ}$ and $90^{\circ} \mathrm{W}$ ) is larger than $1 \mathrm{~K}$ and the other less than -1 $\mathrm{K}$. A composite is constructed by normalizing the data of each group member according to the corresponding CTI and then taking the difference between the two groups. As such, the composite anomalies correspond to a 2-K departure of the CTI from its basic state. The trend is simply calculated as the difference between the beginning (2001-20) and the end (2081-2100) of the twenty-first century; the difference, when compared to 
TABLE 1 . The WCRP CMIP3 model variables used in this study.

\begin{tabular}{|c|c|c|c|c|c|}
\hline Model & Resolution & SST & $\begin{array}{l}\text { Temperature } \\
u \text {-wind }\end{array}$ & $v$-wind & Surface wind \\
\hline $\begin{array}{l}\text { Bjerknes Centre for Climate Research Bergen Climate } \\
\text { Model version 2.0 (BCCR-BCM2.0) }\end{array}$ & T63L31 & A2 & A2 & A2, B1 & $\mathrm{A} 2, \mathrm{~B} 1$ \\
\hline $\begin{array}{l}\text { Canadian Centre for Climate Modelling and Analysis } \\
\text { (CCCma) Coupled General Circulation Model, } \\
\text { version } 3.1 \text { (CGCM3.1) }\end{array}$ & T47L31 & A2 & $\mathrm{A} 2, \mathrm{~A} 1 \mathrm{~B}$ & $\mathrm{~A} 2, \mathrm{~A} 1 \mathrm{~B}, \mathrm{~B} 1$ & $\mathrm{~A} 2, \mathrm{~A} 1 \mathrm{~B}, \mathrm{~B} 1$ \\
\hline $\begin{array}{l}\text { Centre National de Recherches Météorologiques } \\
\text { Coupled Global Climate Model, version } 3 \text { (CNRM-CM3) }\end{array}$ & T63L45 & $\mathrm{A} 2$ & $\mathrm{~A} 2, \mathrm{~A} 1 \mathrm{~B}$ & $\mathrm{~A} 2, \mathrm{~A} 1 \mathrm{~B}, \mathrm{~B} 1$ & $\mathrm{~A} 2, \mathrm{~A} 1 \mathrm{~B}, \mathrm{~B} 1$ \\
\hline $\begin{array}{r}\text { Commonwealth Scientific and Industrial Research } \\
\text { Organisation Mark version 3.0 (CSIRO MK3.0) }\end{array}$ & T63L18 & $\mathrm{A} 2$ & & & \\
\hline GFDL Climate Model version 2.0 (CM2.0) & $2.5 \times 2 \mathrm{~L} 24$ & A2 & $\mathrm{A} 2, \mathrm{~A} 1 \mathrm{~B}$ & $\mathrm{~A} 2, \mathrm{~A} 1 \mathrm{~B}, \mathrm{~B} 1$ & $\mathrm{~A} 2, \mathrm{~A} 1 \mathrm{~B}, \mathrm{~B} 1$ \\
\hline GFDL Climate Model version 2.1 (CM2.1) & $2.5 \times 2 \mathrm{~L} 24$ & A2 & $\mathrm{A} 2, \mathrm{~A} 1 \mathrm{~B}$ & $\mathrm{~A} 2, \mathrm{~A} 1 \mathrm{~B}, \mathrm{~B} 1$ & $\mathrm{~A} 2, \mathrm{~A} 1 \mathrm{~B}, \mathrm{~B} 1$ \\
\hline Goddard Institute for Space Studies (GISS) Model E-R & $5 \times 4 \mathrm{~L} 20$ & A2 & $\mathrm{A} 2$ & $\mathrm{~A} 2, \mathrm{~B} 1$ & $\mathrm{~A} 2, \mathrm{~B} 1$ \\
\hline $\begin{array}{l}\text { Institute of Numerical Mathematics Coupled Model, } \\
\text { version 3.0 (INM-CM3.0) }\end{array}$ & $5 \times 4 \mathrm{~L} 21$ & $\mathrm{~A} 2$ & $\mathrm{~A} 2, \mathrm{~A} 1 \mathrm{~B}$ & $\mathrm{~A} 2, \mathrm{~A} 1 \mathrm{~B}, \mathrm{~B} 1$ & $\mathrm{~A} 2, \mathrm{~A} 1 \mathrm{~B}, \mathrm{~B} 1$ \\
\hline $\begin{array}{l}\text { L'Institut Pierre-Simon Laplace Coupled Model, } \\
\text { version } 4 \text { (IPSL CM4) }\end{array}$ & $2.5 \times 3.75 \mathrm{~L} 19$ & $\mathrm{~A} 2$ & $\mathrm{~A} 2, \mathrm{~A} 1 \mathrm{~B}$ & $\mathrm{~A} 2, \mathrm{~A} 1 \mathrm{~B}, \mathrm{~B} 1$ & $\mathrm{~A} 2, \mathrm{~A} 1 \mathrm{~B}, \mathrm{~B} 1$ \\
\hline $\begin{array}{l}\text { Model for Interdisciplinary Research on Climate 3.2, } \\
\text { medium-resolution version [MIROC3.2(medres)] }\end{array}$ & T42L20 & A2 & A2 & A2, B1 & A2, B1 \\
\hline Max Planck Institute (MPI) ECHAM5 & T63L31 & $\mathrm{A} 2$ & $\mathrm{~A} 2, \mathrm{~A} 1 \mathrm{~B}$ & $\mathrm{~A} 2, \mathrm{~A} 1 \mathrm{~B}, \mathrm{~B} 1$ & $\mathrm{~A} 2, \mathrm{~A} 1 \mathrm{~B}, \mathrm{~B} 1$ \\
\hline $\begin{array}{l}\text { Meteorological Research Institute Coupled General } \\
\text { Circulation Model, version 2.3.2a (MRI CGCM2.3.2a) }\end{array}$ & T42L30 & $\mathrm{A} 2$ & $\mathrm{~A} 2$ & A2 & A2 \\
\hline $\begin{array}{l}\text { National Center for Atmospheric Research (NCAR) } \\
\text { Community Climate System Model, version } 3 \text { (CCSM3.0) }\end{array}$ & T42L26 & A2 & A2 & A2 & A2 \\
\hline NCAR Parallel Climate Model version 1 (PCM1) & T42L18 & $\mathrm{A} 2$ & A2 & A2 & A2 \\
\hline $\begin{array}{l}\text { Met Office (UKMO) Third Hadley Centre Coupled } \\
\text { Ocean-Atmosphere GCM (HadCM3) }\end{array}$ & $2.75 \times 2.5 \mathrm{~L} 19$ & A2 & A1B & A1B & A1B \\
\hline $\begin{array}{l}\text { UKMO Hadley Centre Global Environmental Model } \\
\text { version } 1 \text { (HadGEM1) }\end{array}$ & $1.875 \times 1.25 \mathrm{~L} 38$ & $\mathrm{~A} 2$ & $\mathrm{~A} 2, \mathrm{~A} 1 \mathrm{~B}$ & $\mathrm{~A} 2, \mathrm{~A} 1 \mathrm{~B}$ & A2, A1B \\
\hline
\end{tabular}

the ENSO composites, is then rescaled to correspond to a $2-\mathrm{K}$ increase in the CTI.

To examine model dependence and sensitivity to model configurations, gridded global monthly data for the various models available from the World Climate Research Programme (WCRP) Coupled Model Intercomparison Project, phase 3 (CMIP3) multimodel dataset (http://www-pcmdi.llnl.gov/ipcc/about_ipcc. php) are also employed. Occasionally, to increase the sample size for the scaling/sensitivity analysis, scenarios with less aggressive greenhouse gas (GHG) forcing (A1B with $\mathrm{CO}_{2}$ stabilized at 720 ppm; B1 with $\mathrm{CO}_{2}$ stabilized at $550 \mathrm{ppm}$ ) are also used. See Table 1 for the models and scenarios used for the analyses.

To describe and understand the circulation changes, the following metrics are defined and calculated.

\section{a. Meridional mass streamfunction $\Psi$}

We compute the zonal mean mass streamfunction by vertically integrating the zonal mean density-weighted meridional wind from the top model level downward. The poleward edge of the $\mathrm{HC}$ is then determined by the first zero-crossing latitude of $500 \mathrm{hPa} \psi$ as one moves poleward from the extrema of the streamfunction in each hemisphere.

\section{b. Maximum surface westerly latitude $Y_{\max }$}

To relate the expansion of the $\mathrm{HC}$ to the poleward shift of the eddy-driven jet, we also compute the latitude of maximum surface westerly $\left(Y_{\max }\right)$, which is defined as the latitude (computed by linear interpolation) where the meridional derivative of the zonal mean surface wind with respect to latitude $\left(d U_{s} / d y\right)$ becomes zero at the peak of the surface westerly winds.

\section{c. Tropopause height}

Following the World Meteorological Organization (1957) definition, the tropopause height is estimated from temperature data as the lowest pressure level at which the lapse rate decreases to $2 \mathrm{~K} \mathrm{~km}^{-1}$, using the algorithm of Reichler at al. (2003).

\section{d. Eddy momentum flux spectrum}

The latitude-phase speed spectrum of eddy momentum flux is used to characterize the meridional propa- 


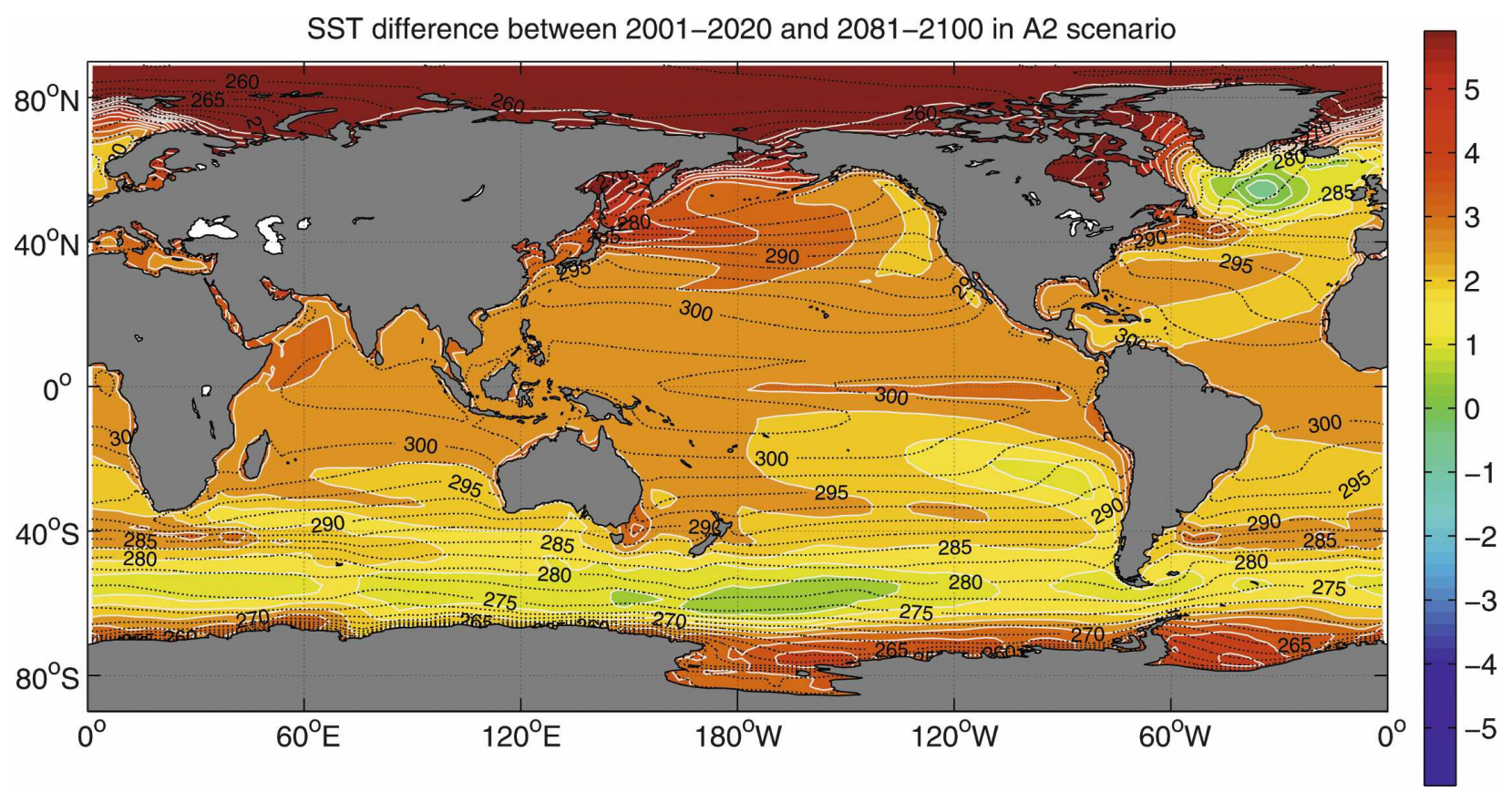

FIG. 1. Multimodel ensemble mean trend in annual mean SST (K) between 2001-20 and 2081-2100 based on 16 simulations of the A2 scenario. Areas warmer than $4 \mathrm{~K}$ are blanked out with brown color.

gation of baroclinic eddies (Randel and Held 1991; Kim and Lee 2004; Son and Lee 2005; Chen et al. 2007). The eddy momentum fluxes are first decomposed as a function of zonal wavenumber and frequency, using the mixed space-time cross-spectral analysis (Hayashi 1971). Following Randel and Held (1991), the cospectrum is transformed as a function of zonal wavenumber and angular phase speed. Finally, the momentum flux spectrum at each latitude is summed over wavenumbers, resulting in a spectrum density as a function of latitude and angular phase speed. In the figures, we use angular phase speed multiplied by the earth's radius to present the cospectrum.

Daily time series of length 120 days in DecemberMarch (DJFM) are used to calculate the space-time spectrum for each year. The resolution in the phase speed space is limited by daily sampling (as indicated by the blank area near zero phase speed in Figs. 9 and 10). Since we can only access the daily output of the GFDL CM2.1 model, the spectrum analysis is conducted only for the A2 scenario simulation by this model.

\section{Characteristics of SST warming}

Figure 1 shows the SST difference between 2001-20 and $2081-2100$ in A2 scenario simulations by 16 IPCC models (Table 1). The multimodel mean exhibits a clear El Niño-like response in the tropical Pacific, with enhanced warming in the equatorial central and eastern Pacific. Of the 16 models, 14 show intensified warming in the equatorial Pacific, and an El Niño-like SST pattern appears in all the models (MPI ECHAM5, GFDL CM2.0, GFDL CM2.1, MIROC3.2, and UKMO HadCM3) that have been identified by previous studies (van Oldenborgh et al. 2005; Yamaguchi and Noda 2006) to have realistic balances of ENSO feedbacks. The mechanisms for the El Niño-like SST response to global warming have been widely studied. The most probable one may be rooted in the weakening of the tropical atmospheric circulation in a warmed climate (Knutson and Manabe 1995; Vecchi et al. 2005; Vecchi and Soden 2007; Zhang and Song 2006; Held and Soden 2006). The slowdown of the zonal overturning of air across the Pacific (i.e., the Walker circulation) leads to a decrease of the surface easterlies which relaxes the zonal thermocline slope toward a flatter condition and initiates a chain of air-sea feedbacks toward a more El Niño-like condition. The so-called ocean-thermostat mechanism (Cane et al. 1997; Seager and Murtugudde 1997; Clement et al. 1996), which favors a warming at warm pool over the strong upwelling eastern Pacific, tends to counteract against the El Niño-like feedback. The net outcome from these two competing mechanisms turns out to be something in between, with somewhat more dominance by the latter: warmer equatorial SST relative to the off-equatorial region, intensified 
convection over the central equatorial Pacific (more westward located than that associated with canonical El Niño), and an associated anomalous zonal overturning circulation that projects only weakly, if any, on the canonical Southern Oscillation (van Oldenborgh et al. 2005). In summary, while the tropical SST response should not be considered completely El Niño-like, there are still many key commonalities, such as the enhanced warming and convection at the central and eastern equatorial Pacific.

In the extratropics, most models simulate an intensified warming near the annual mean SST front associated with the Kuroshio and its extension, while the response in the Southern Ocean is characterized by a circumpolar belt of suppressed warming centered at about $55^{\circ} \mathrm{S}$. The mechanisms for these extratropical features are beyond the scope of this study.

\section{Zonal mean circulation}

The analysis in this section is based primarily on simulations with the GFDL CM2.1 model. Nevertheless, the features discussed are not unique to this model and have been found in the majority of the IPCC models or in observations. Additionally, for brevity, in some plots only the December-February (DJF) season is presented. But many of the features shown about the GHG-induced warming are not limited to boreal winter, as will be noted specifically in the relevant parts of the text.

Shown in the left panels of Fig. 2 are the El Niño minus La Niña composites for the air temperature, zonal mean zonal wind, and the tropopause pressure level, those being derived from the difference between 14 warm years and 12 cold years. The interhemispheric symmetry of both temperature and zonal wind bears great resemblance to regression patterns associated with the observed El Niño (Seager et al. 2003; L'Heureux and Thompson 2006). As discussed by Seager et al. (2003), the warming in the deep tropics can be plainly understood as a consequence of the increase in tropical Pacific SST and the anomalous heat flux from ocean to the atmosphere; the maximum warming at the upper-tropical troposphere, a structure also found in the observations, can be related to the quasi-moist adiabatic behavior of the tropical atmosphere in responding to the increase in moist static energy in the boundary layer. The tropospheric cooling in midlatitudes between $25^{\circ}$ and $40^{\circ}$ in the Northern Hemisphere (NH) and $35^{\circ}$ and $50^{\circ}$ in the Southern Hemisphere $(\mathrm{SH})$ is produced by eddy-driven upward motion, further evidence for which will be provided later in the paper. Consistent with the temperature anomalies, the tropo- pause level increases in the deep tropics but decreases near the boundary of the tropics. One can think of the tropics as the latitudinal extent within which the tropopause height exceeds a certain threshold, and thus the tropics shrink under El Niño conditions.

As in observations, the tropospheric zonal wind intensifies (weakens) near the equatorward (poleward) flank of the jet, resulting in a strengthening and equatorward shift of the jet. The zonal wind changes poleward of $20^{\circ} \mathrm{N}$ or $30^{\circ} \mathrm{S}$ have a quasi-barotropic structure. These features have been interpreted (Robinson 2002; Seager et al. 2003) as a chain of feedbacks-initiated by the intensified subtropical jet by the tropical heatinginvolving the subtropical critical surface (where the phase speed of the eddies equals the zonal wind speed) for the equatorward wave propagation. Later in section $5 \mathrm{~b}$, we will show that the picture proposed by Robinson and Seager et al. is consistent with the response in the full spectrum of the eddy momentum fluxes.

The temperature response to global warming (Fig. $2 b$ ) is distinct from the response to El Niño, although both show warming in the tropics and accentuated warming in the upper-tropical troposphere. The midtropospheric temperature warms most at the latitudes where the El Niño tends to cool most. Thus, the associated meridional temperature gradient in the subtropical-to-midlatitude midtroposphere is exactly opposite to that associated with the El Niño. Under global warming, the features shared in common in both hemisphere include an enhanced upper-tropospheric warming that leads to a more stable stratification from the tropics to midlatitudes; and a cooling in the stratosphere (or less warming relative to the troposphere for the case of $\mathrm{SH}$ ), which gives rise to a intensified meridional temperature gradient at midlatitudes near the tropopause. The former has been ascribed to the quasimoist adiabatic adjustment to the increase of surface moist entropy through convection in the tropics $(\mathrm{Xu}$ and Emanuel 1989) and through baroclinic eddies in the midlatitudes (Juckes 2000; Frierson et al. 2006; Frierson 2006, 2008); the latter is most likely of a radiative origin (Manabe and Wetherald 1967; Hansen et al. 1997). As we will demonstrate later in section 5, both features have important bearings as to the mechanisms of the Hadley cell expansion.

The temperature structure near the tropopause projects upon a ubiquitous increase in the tropopause height with enhancements near the boundaries of the tropics (Fig. 2f). Therefore, in a warmed climate, the tropics broaden, in stark contrast to El Niño conditions. Consistent with the temperature changes, the upperlevel subtropical wind intensifies yet the midlatitude jet stream shifts poleward in contrast to the equatorward 
(a) temperature, El Nino - La Nina

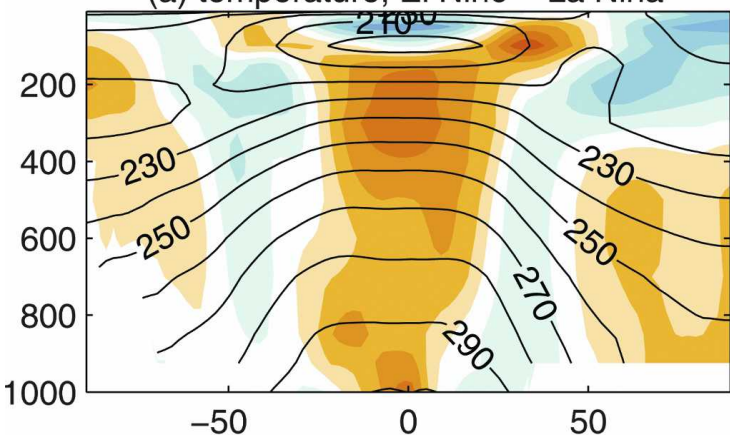

(c) u-wind, El Nino - La Nina

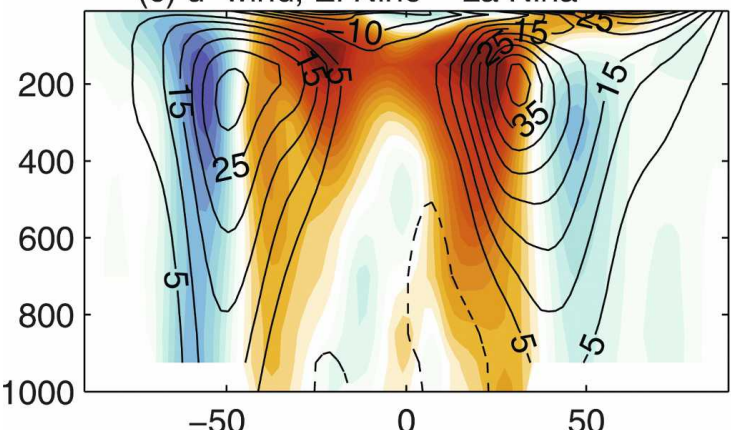

(e) tropopause, El Nino - La Nina

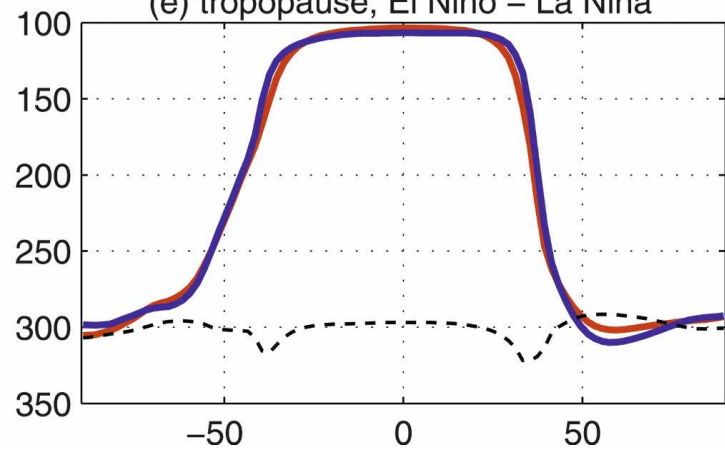

(b) temperature, trend

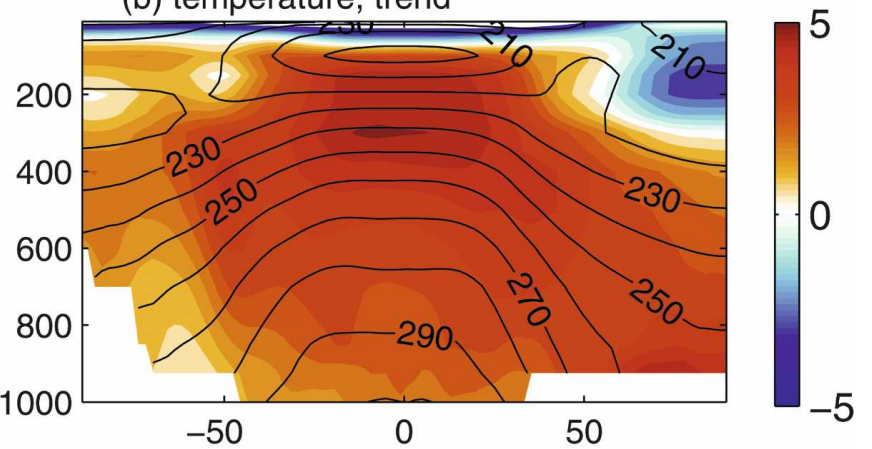

(d) u-wind, trend

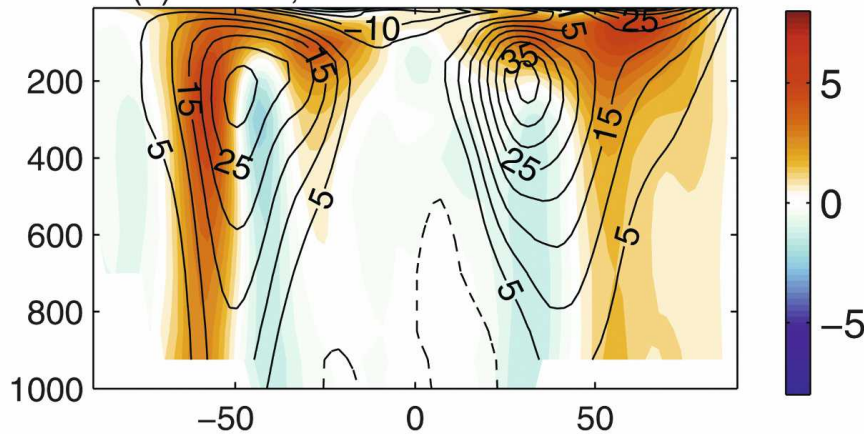

(f) tropopause, trend

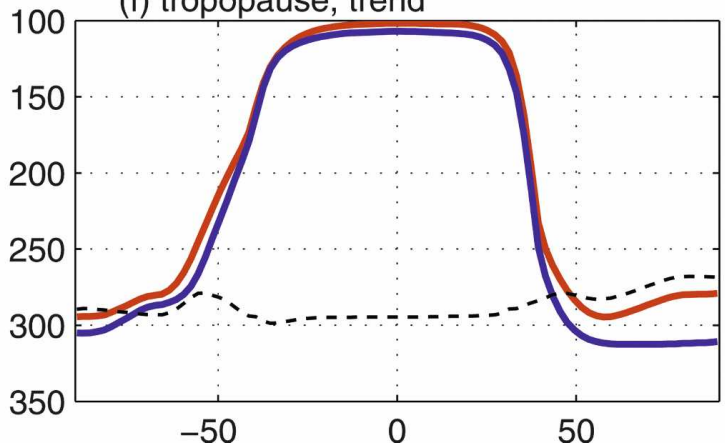

Fig. 2. (top) Temperature (K), (middle) zonal wind $\left(\mathrm{m} \mathrm{s}^{-1}\right)$, and (bottom) tropopause height (hPa) for (left) the El Niño-La Niña composite and (right) the trend during DJF months. Shadings represent the anomalous fields, contours the climatological mean fields. The blue (red) lines in the bottom panels are the pressure levels of the tropopause for the La Niña (El Niño) composite and 2001-20 (2081-2100) mean; the dashed lines are the difference of El Niño - La Niña (left) and 2081-2100 - 2001-20 (right), respectively, offset by $300 \mathrm{hPa}$ for the display purpose.

jet movement under El Niño conditions (cf. Figs. 2c and $2 \mathrm{~d})$. One key distinction is that the maximum temperature gradient associated with global warming takes place at higher latitudes and strengthens the poleward flank of the jet. The mechanism for the jet shift and the expansion of the $\mathrm{HC}$ is the focus of this study and will be elaborated on later. The maximum subtropical to midlatitude warming in the troposphere, the poleward shift of the jet, and the broadening of the tropics appear to be ubiquitous to both hemispheres in all seasons.

DJF 500-hPa geopotential height also shows some interesting distinctions between the El Niño composite and GHG-induced trend (Fig. 3). The GFDL CM2.1 can realistically capture the canonical Pacific-North America teleconnection in response to El Niño, with low anomalies extending downstream to the America and midlatitude Atlantic (Fig. 3a). In the SH, the wave train from the northwest of Australia to the Ross Sea forms a pattern nearly symmetric about the equator with its $\mathrm{NH}$ counterpart; it resembles markedly the ENSO teleconnection observed in the SH (Fig. 2 in Garreaud and Battisti 1999). The mid-high-latitude response is more zonally symmetric outside of the South Pacific. In the zonal mean 500-hPa height field, El Niño produces a midlatitude trough and a high to the poleward side in each hemisphere. This is exactly opposite 
(a) El Nino - La Nino

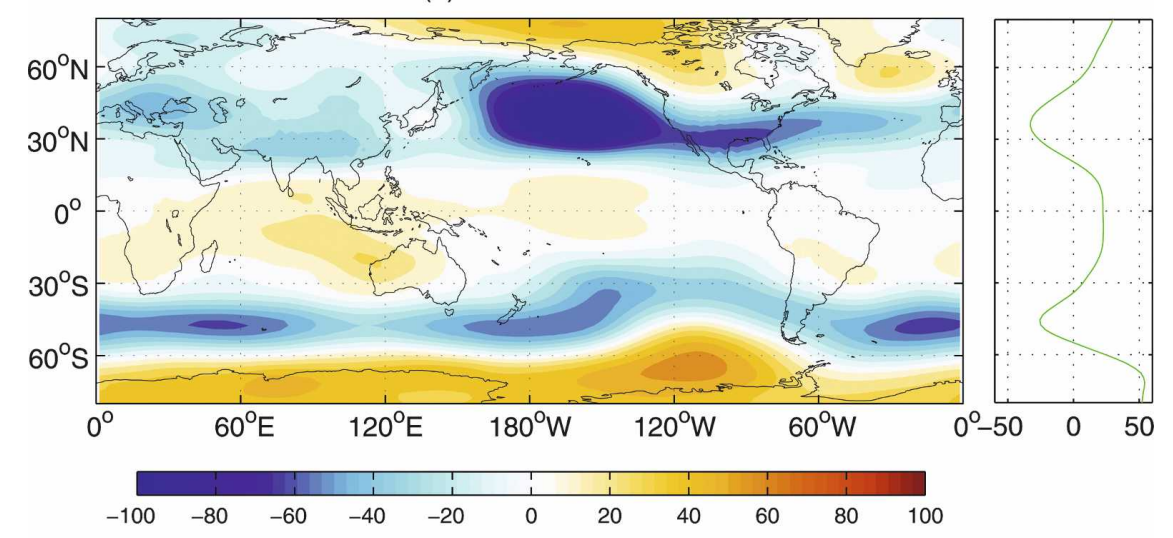

(b) trend

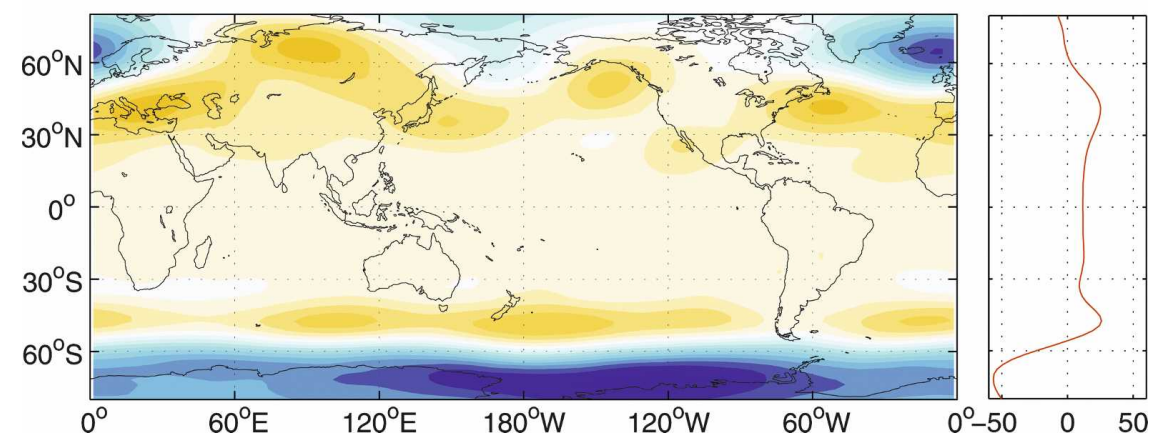

FIG. 3. DJF 500-hPa geopotential height field (m) for (a) El Niño-La Niña composite and (b) trend. The right side panels are the zonal mean of the corresponding field.

to the global warming response (Fig. 3b), which is characteristic of a midlatitude ridge and a high-latitude low, a pattern that projects positively onto the annular mode in each hemisphere.

Contrasting the zonal mean mass streamfunction (Fig. 4) of El Niño versus La Niña during the peak season (DJF months), the Hadley cells in both hemispheres tend to intensify and contract equatorward in the tropics, and the Ferrell cells move equatorward as well, especially in the SH. The vertical motions match well with the diabatic heating in both tropics and extratropics (not shown). While the vertical motions within the tropics can be well explained by the convective heating, the balance between the dynamical motion and the diabatic heating away from the tropics does not necessarily mean that the former is driven by the latter. Adding a subtropical zonal wind anomaly onto a linearized quasigeostrophic model, Seager et al. (2003) showed that eddy dynamics, without any explicit diabatic processes, can produce a midlatitude cooling through Rossby wave propagation and refraction. Thus, the interhemispherically symmetric midlatitude cooling (near $30^{\circ} \mathrm{N}$ in the $\mathrm{NH} ; 45^{\circ} \mathrm{S}$ in the $\mathrm{SH}$ ) and the corre- sponding ascending motion should be interpreted as being eddy driven.

The meridional overturning circulation response to GHG forcing is characterized by a weakening and poleward expansion of the $\mathrm{HC}$ and a poleward displacement of Ferrell cell. Another interesting feature consistent with the tropopause rise is that the Hadley circulation tends to grow deeper under global warming. Both the weakening and the poleward expansion of the HC under global warming appear to be robust among the climate models ( $\mathrm{Lu}$ et al. 2007). The weakening of the tropical atmospheric circulation has been argued to be thermodynamically rooted (Knutson and Manabe 1995; Held and Soden 2006). In the tropics, the free atmospheric temperature is close to the moist adiabat. On a moist adiabat, the variation of dry static stability measured by $\partial \theta / \partial p$ averaged over the troposphere is proportional to that of boundary layer mixing ratio $q$. Thus, the static stability in the tropics increases with the surface temperature following Clausius-Clapeyron relation as the column-integrated moisture does (i.e., $\delta(\partial \theta / \partial p) /(\partial \theta / \partial p) \approx \delta q / q)$. The leading-order thermodynamical balance in the upward branch of the $\mathrm{HC}$ is 
(a) El Nino - La Nina

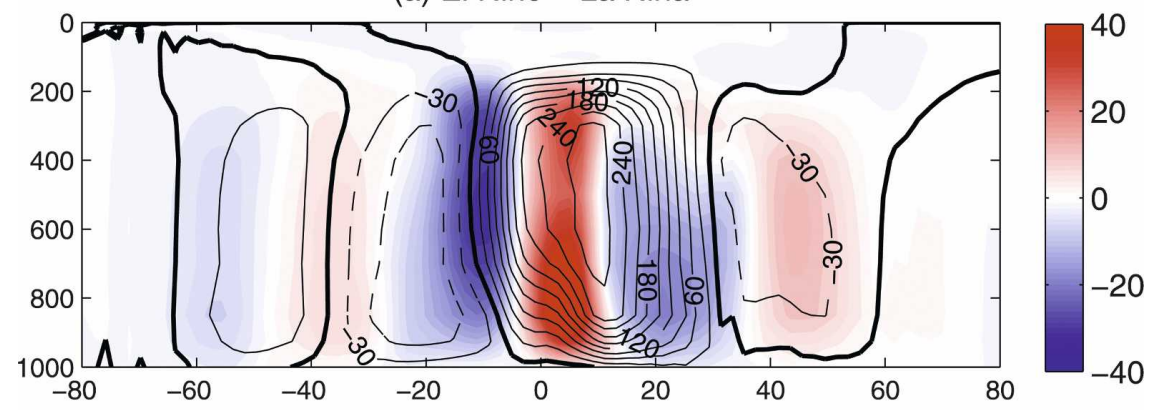

(b) trend

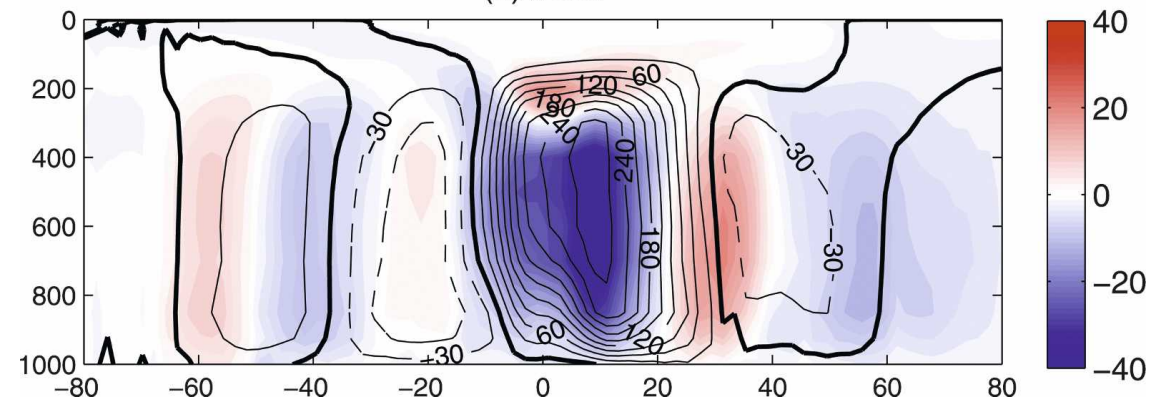

FIG. 4. DJF Zonal mean mass streamfunction $\left(1 \times 10^{9} \mathrm{Kg} \mathrm{s}^{-1}\right)$ for (a) El Niño-La Niña composite and (b) trend. Contours are the climatological mean streamfunction.

between the diabatic heating and the dynamical cooling associated with the updraft, that is, $Q=\omega \partial \theta / \partial p$, or in the form of fractional change, $\delta Q / Q=\delta \omega / \omega+\delta(\partial \theta /$ $\partial p) /(\partial \theta / \partial p)$. Neither of the primary components of the diabatic heating (radiative cooling or condensational heating) increases as rapidly as the increase in stability (i.e., $\delta Q / Q<\delta q / q$ ). In fact, near the warm pool region where the mean ascending motion takes place, a significant amount of the GHG-induced increase of heating by condensation is compensated by enhanced radiative cooling (Knutson and Manabe 1995). Therefore, it is hard for the rate of change in diabatic heating to keep up with that of static stability, and consequently, the tropical ascent must weaken at a rate $\delta \omega / \omega=\delta Q / Q-$ $\delta q / q$. The mechanism for the expansion of the Hadley circulation is the subject of focus of the next section.

In accordance with their distinct circulations, the hydrological response also demonstrates some interesting contrast between El Niño and global warming conditions (Fig. 5). For both cases, the precipitation minus evaporation $[P-E$; December-April (DJFMA)] increases at the equator and decreases over its neighboring latitudes. In this sense, the zonal mean hydrological response to global warming is somewhat like El Niño, but the magnitude in the former case is at most half of that in the later, despite that both curves have been scaled to correspond to a 2-K CTI discursion from climatology. In the latitudinal band between $25^{\circ}$ and $45^{\circ} \mathrm{N}$ in the $\mathrm{NH}$ and $35^{\circ}$ and $55^{\circ} \mathrm{S}$ in the $\mathrm{SH}$, El Niño generates an above-normal $P-E$ while global warming produces a deficit in $P$ and $P-E$; as such, the former displaces the outer boundary of the subtropical dry zone (defined as area where $P-E<0$ ) equatorward, while the latter displaces the boundary poleward. The increased equatorial precipitation and decreased subtropical precipitation with global warming can be ascribed to increased atmospheric moisture content (Allen and Ingram 2002; Held and Soden 2006), and

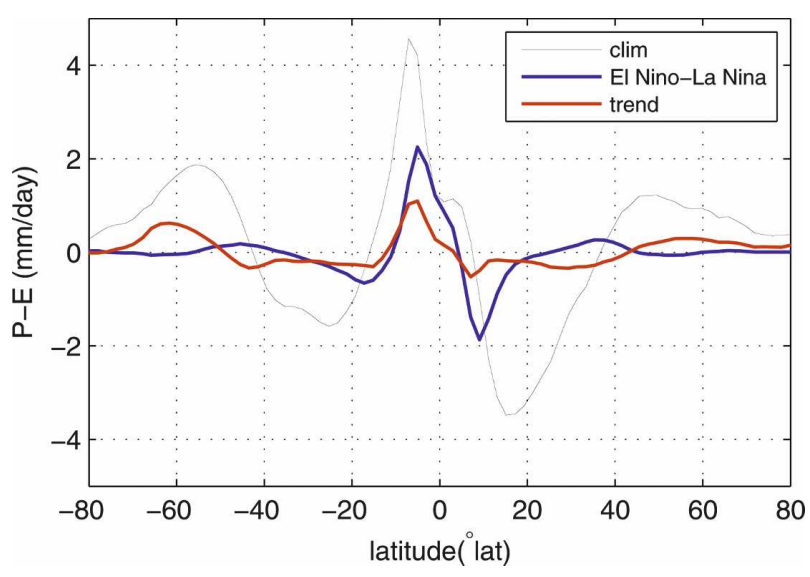

FIG. 5. DJFMA mean $P-E$ for El Niño-La Niña composite (blue) and trend (red). The climatologically mean $P-E$ is plotted (black) as a reference. 
happen despite the weakening of the Hadley circulation. The tropical hydrological cycle response to El Niño, on the other hand, is amplified by the strengthening of the Hadley circulation.

The poleward expansion of the boundary of the subtropical dry zone (defined as the latitude where $P=E$ ) is tightly tied to the expansion of the subsidence area of the HC (Lu et al. 2007). For the complex climate systems portrayed by the coupled climate models, while it may seem difficult to argue for a cause-effect relationship between the expansion of the dry zone and the HC, we attempt to probe possible mechanisms that do not directly depend on the diabatic heating and therefore, arguably, hold accountable dynamically for the changes in both the $\mathrm{HC}$ and the subtropical dry zone.

\section{Possible causes for $\mathrm{HC}$ expansion}

\section{a. Subtropical baroclinicity}

Our understanding of the extent of the $\mathrm{HC}$ has been guided by two alternative views on dynamical/thermodynamical controls of the HC. The classic inviscid theory for axisymmetric circulations (Held and Hou 1980), which assumes that the upper-tropospheric wind is angular momentum conserving and that the heating and cooling for the atmosphere are balanced within the $\mathrm{HC}$, predicts that the meridional extent of the $\mathrm{HC}$ scales with the height of the tropical tropopause and the equator-to-pole temperature difference in radiative equilibrium, while having no explicit dependence on static stability. The second view sees the width of the $\mathrm{HC}$ as being determined by the poleward extent to which the angular momentum conserving wind in the upper troposphere increases poleward until the resulting vertical shear becomes baroclinically unstable (Held et al. 2000). This leads to an alternative scaling for the extent of the $\mathrm{HC}$, which predicts a widening of the $\mathrm{HC}$ with an increase in the gross static stability, as the critical criterion for baroclinic instability is inversely proportional to the static stability.

In both idealized atmospheric models and fully coupled models, the latter scaling appears to better capture the dynamics of the $\mathrm{HC}$ width. With an idealized dry GCM, Walker and Schneider (2006) found a large sensitivity of the $\mathrm{HC}$ width to the lapse rate parameter in their convective parameterization, a factor that they interpret with the Held et al. (2000) scaling. With a set of aquaplanet simulations using both a full GCM and an idealized moist GCM, Frierson et al. (2007) showed that the Held et al. (2000) scaling fits the simulated HC widths over a wide parameter range. In coupled climate model simulations of the A2 scenario, Lu et al. (2007) investigated the applicability of the two scaling theories and found that the second scaling is more relevant to the dynamics that controls the extent of the $\mathrm{HC}$ in the present-day climate.

According to Walker and Schneider (2006), the summer cell resides far from the nearly inviscid regime that conserves angular momentum, and the better part of the cell is predominantly driven by the eddy activity fluxes. Therefore, in the following investigation of the mechanism of the HC expansion for both winter and summer cells during DJF, we relax the assumption of angular momentum conservation. In so doing, we generalize the meaning of the Held et al. (2000) scaling to a notion that it is the momentum forcing of the baroclinic eddies that determines the poleward extent of the Hadley cell; it also allows us to take into account of the effect of wind shear in the evaluation of baroclinicity.

Using the Phillips (1954) baroclinic instability criterion (without the loss of the generality regarding the nature of the problem), the metric for evaluating the baroclinic criticality becomes

$$
C \equiv \frac{f^{2}\left(u_{500}-u_{850}\right)}{\beta g H\left(\theta_{500}-\theta_{850}\right) / \Theta_{0}},
$$

where the vertical wind shear and potential temperature difference are taken between 500 and $850 \mathrm{hPa}$, and $H$ represents the thickness of the air column between 500 and $850 \mathrm{hPa}$ and is simply set to be a constant (5000 $\mathrm{m})$. In deriving (1), only the lower troposphere is considered, because baroclinic eddy growth is more sensitive to the lower-level than to the upper-level baroclinicity (Held and O'Brien 1992). Again, taking advantage of the simulations of global warming scenarios by various CMIP3 models (9 from A1B; 14 from A2), we examine to what extent the expansion of the HC per se and the scatter thereof across models can be accounted for by the reduction of the subtropical baroclinicity $C$.

In Fig. 6a, the displacements of the $\mathrm{SH}$ summer (DJF) boundary of the HC during the twenty-first century (i.e., 2081-2100 minus 2001-20) are plotted against the changes in the baroclinic criticality $C$ averaged over a $25^{\circ}$ latitudinal range to the immediate equatorward side of the mean position of the midlatitude jet, where eddies are believed to play a crucial role in defining the boundary of the HC. First of all, we note that the ensemble mean of simulations does indeed have a decrease in criticality of the subtropics, with an average reduction of approximately -0.02 . Furthermore, the models with larger reduction in $C$ tend to produce larger $\mathrm{HC}$ expansion. The regression line for the $\mathrm{HC}$ boundaries intercepts the $C=0$ line at about 0 , implying that the SH HC boundary hardly moves without 
(a) Phillips criticality

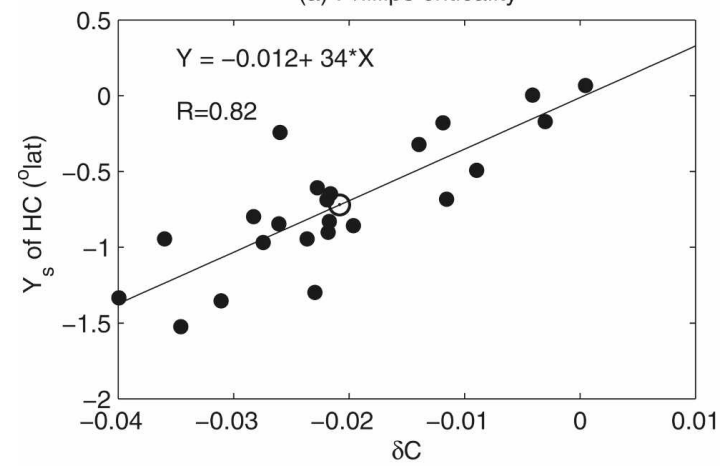

(c) Phillips criticality (wind shear)

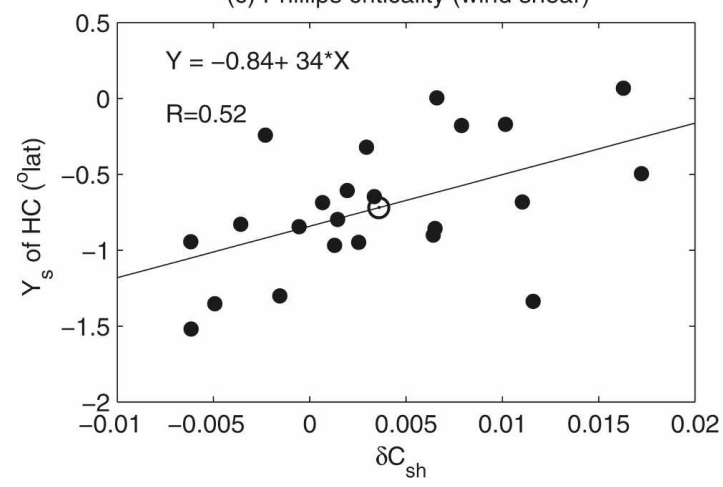

(b) Phillips criticality (stability)

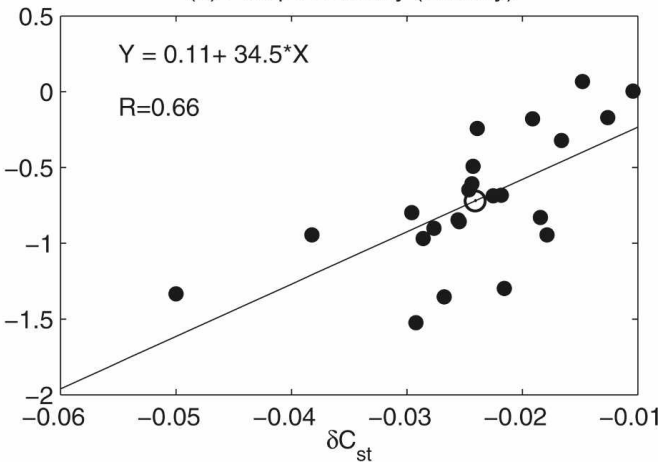

FIG. 6. Relationship between the change in Phillips' criticality $\delta C$ and the expansion of the Hadley cell in SH DJF. (a) Total change of $\delta C$ due to both stability and wind shear; (b) $\delta C_{\text {st }}$ due to the change of static stability alone; (c) $\delta C_{\mathrm{sh}}$ due to change of wind shear alone. The open circles denote the ensemble mean values. The criticality is averaged over a $25^{\circ}$-wide lat range to the equatorward side of the midlatitude jet. For DJF, there is only one jet maximum in the upper troposphere in each hemisphere. changing baroclinicity. The reduction in $C$ can be further decomposed into contributions from the increase of static stability; that is,

$$
\delta C_{\mathrm{st}} \approx-\frac{f^{2}\left(u_{500}-u_{850}\right)_{1} \delta\left(\theta_{500}-\theta_{850}\right)}{\beta g H\left(\theta_{500}-\theta_{850}\right)_{1}^{2} / \Theta_{0}},
$$

and decrease of vertical wind shear; that is,

$$
\delta C_{\mathrm{sh}}=\frac{f^{2} \delta\left(u_{500}-u_{850}\right)}{\beta g H\left(\theta_{500}-\theta_{850}\right)_{1} / \Theta_{0}} .
$$

The subscript 1 in (2) and (3) indicates the values calculated from the period 2001-20 and the $\delta$ term the difference of period 2081-2100 minus 2001-20. Increases in the subtropical static stability are of primary importance in decreasing the criticality, with an ensemble mean decrease of -0.025 due to static stability (Fig. 6b). Changes in the wind shear cause the criticality to increase by a small amount on average, although the variation of wind shear changes contributes noticeably to the variation of the baroclinicity (Fig. 6c).

For the NH DJF months, there is again a decrease in criticality for the ensemble mean of approximately -0.013 . However, the poleward expansion of the $\mathrm{HC}$ across different models is much less correlated with the changes in the subtropical baroclinicity (Fig. 7a). This is possibly due to factors other than baroclinic eddies, such as stationary waves and large land-sea contrast, which can exert significant influences on the overturning circulation. Still, the correlation between the displacements of the NH HC boundaries and the variations in the baroclinicity is significant beyond $95 \%$ confidence level (Fig. 7a). Again the dominance of the static stability in creating the decrease in criticality is discernable by comparing the ensemble mean and variations in the baroclinicity caused by static stability (Fig. 7b) with that by wind shear (Fig. 7c).

The intimate connection of the $\mathrm{HC}$ extent to the eddy dynamics in SH summer is also manifested in its relationship to the eddy-driven jet. Figure 8 presents a scatterplot of the displacements of the $\mathrm{HC}$ boundaries during the twenty-first century versus those of the eddy-driven jet position, measured by the latitude of the maximum surface zonal wind $\left(Y_{\max }\right)$. The usage of $Y_{\max }$ is justified by the local momentum balance, that the vertically integrated eddy momentum flux convergence is largely balanced by the surface drag in midlatitudes (except for the relatively small contributions from mountain torque and gravity wave drag), and thus the eddy-driven jet must plausibly collocate with the maximum surface zonal wind. The HC boundary tends to move in concert with the eddy-driven jet in the $\mathrm{SH}$, more so than in the NH. This corroborates the previous notion that baroclinic eddies play key role in setting the boundary of the Hadley circulation, particularly in the 
(a) Phillips criticality

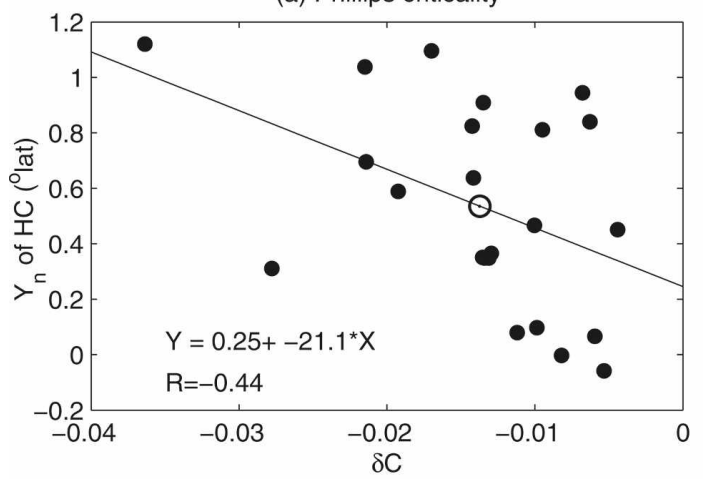

(c) Phillips criticality (wind shear)

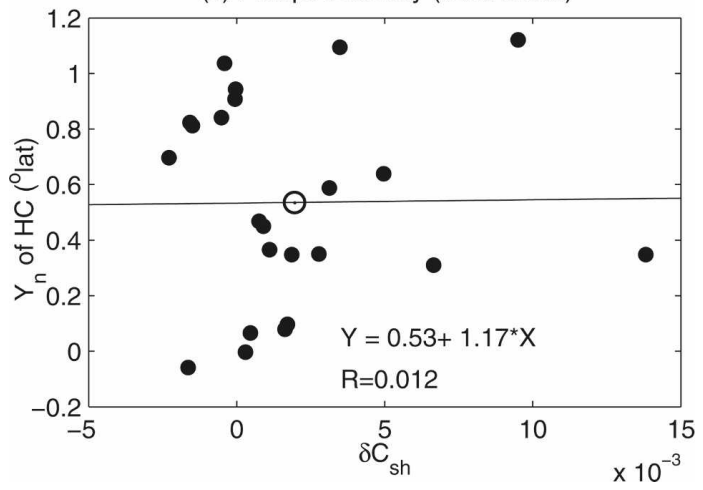

(b) Phillips criticality (stability)

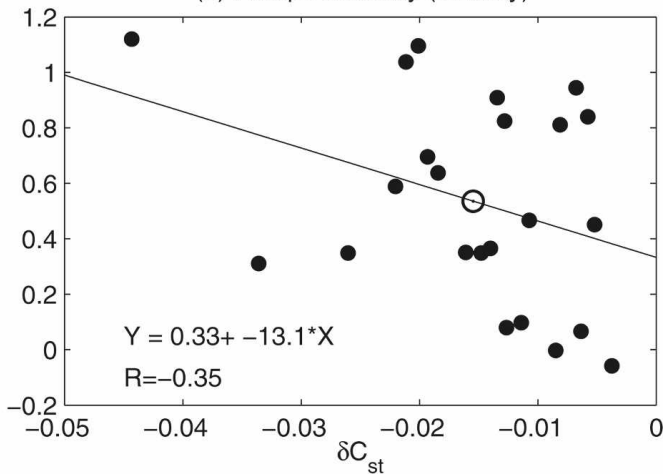

FIG. 7. Same as Fig. 6 except for NH DJF.
SH summer, when the HC and the eddy-driven jet are closely linked.

\section{b. Eddy momentum flux spectrum}

By decomposing the transient eddy momentum flux into components from discrete phase speeds, the different forcing mechanisms for the $\mathrm{HC}$ expansion between La Niña and global warming conditions can be unraveled via the intricate eddy-mean flow interactions near critical latitudes. The cospectra of eddy momentum flux convergence at $250 \mathrm{hPa}$, as a function of angular phase speed $\left(c_{A}=c / \cos \phi\right)$ and latitude, are displayed in Fig. 9 together with the zonal mean zonal wind divided by $\cos \phi$. Near the equatorward flank of the jet, the mean spectra (shadings) are confined poleward of the critical latitudes. This implies that the critical latitude acts as a limit for the equatorward propagation of baroclinic waves, which tend to break $10^{\circ}-20^{\circ}$ latitude before reaching their critical latitudes. As a consequence, the waves with smaller phase speeds can propagate further (a) $\mathrm{SH}$

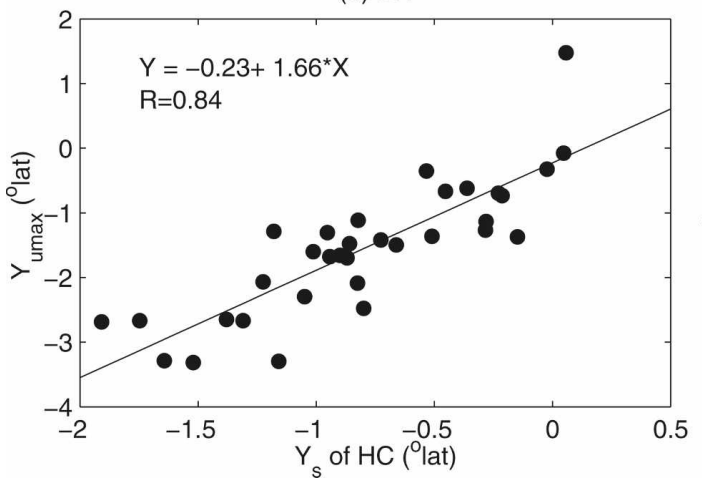

(b) $\mathrm{NH}$

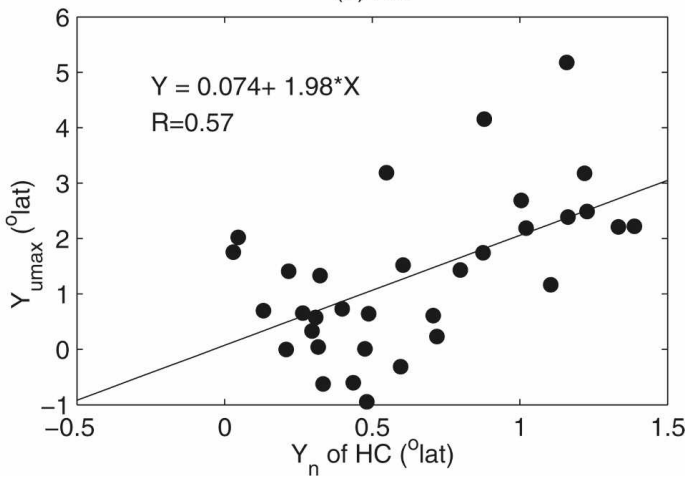

FIG. 8. Relationship between the expansion of the Hadley cell and the shift of the surface wind in (a) SH and (b) NH during DJF. 


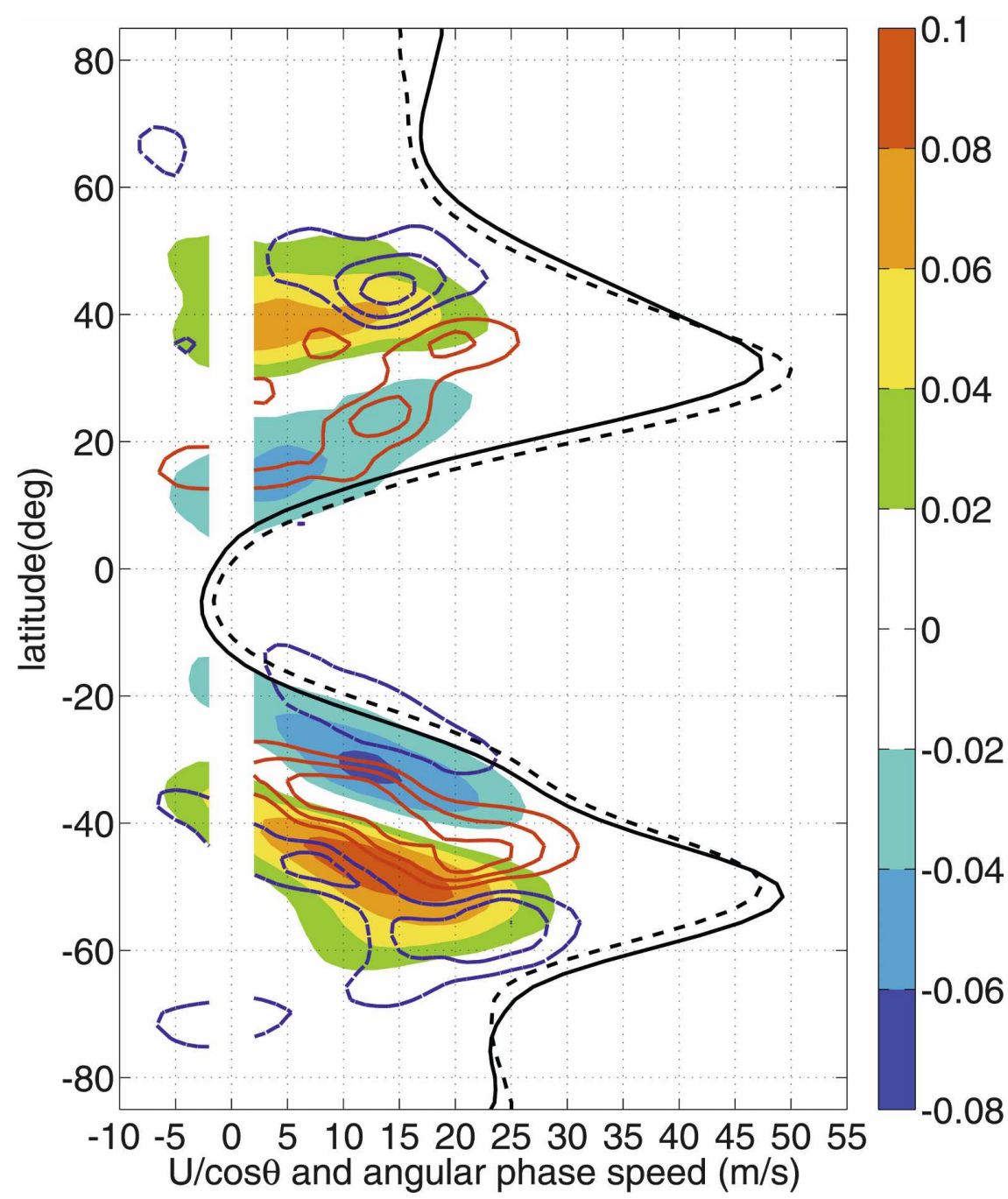

FIG. 9. Cospectra $\left(\mathrm{m} \mathrm{s}^{-1} \mathrm{day}^{-1}\right)$ of eddy momentum flux convergence during DJFM. Shading: climatology; contours: El Niño-La Niña composite. Black solid line: $250 \mathrm{hPa} U / \cos \theta$ during La Niña; dashed line: $U / \cos \phi$ during El Niño. The contour interval is $0.004 \mathrm{~m} \mathrm{~s}^{-1} \mathrm{day}^{-1}$. The red (blue) color denotes positive (negative) values.

into the tropics, while the waves with faster phase speeds are restricted to higher latitudes. The confinement of the eddy activity by the critical latitudes is evidence for the relevance of quasi-linear wave theory to the real atmosphere.

The anomalous cospectra associated with the composite of El Niño minus La Niña are characterized by a systematic equatorward shift of midlatitude waves, whether slow or fast. This is especially clear in the $\mathrm{SH}$. Qualitatively the same ENSO composite pattern is also derived from the 40-yr European Centre for MediumRange Weather Forecasts (ECMWF) Re-Analysis (ERA-40; Chen et al. 2008). As in Robinson (2002) and Seager et al. (2003), we attribute the equatorward displacement of the eddy momentum divergence at the equatorward flank of the spectra to the increase of the thermally driven subtropical wind (dashed line) during the warm phase of the ENSO. The strengthening of the wind at the subtropics draws equatorward the critical latitudes for waves of all phase speeds. As a result, the wave activity can penetrate deeper into the tropics than it otherwise would during the cold phase of the ENSO. This results in an equatorward shift of the eddy momentum spectra as a whole, and hence the shift of the eddy-driven jet and meridional circulation. In the $\mathrm{NH}$, the signature of the critical latitude shift in the El Niño composite is less clear, possibly complicated by the zonally asymmetric lower-boundary conditions.

The eddy cospectra response to GHG forcing (Fig. 10) shows some opposite features to the El Niño composite, that is, a dipole at midlatitudes that shifts the mean spectra poleward. However, unlike the ENSO 


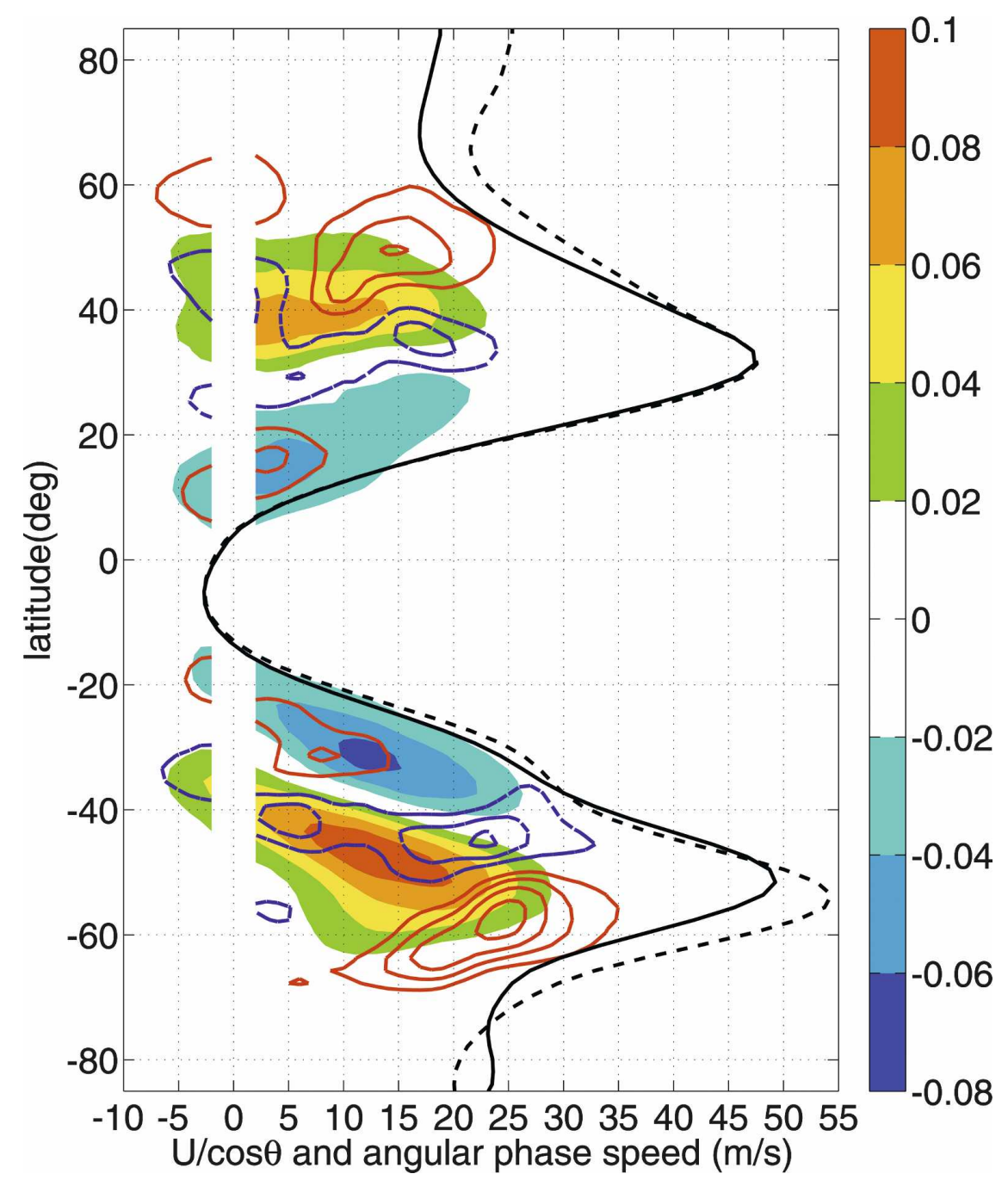

FIG. 10. Cospectra as in Fig. 9 except for trend.

composite, no systematic shift occurs with the critical latitudes; instead, a salient feature accompanying the midlatitude dipole is that the center of the spectra moves toward higher phase speeds. Under the dynamical constraint of the critical latitude, eddies with faster phase speed are trapped in the higher latitudes, and the associated eddy-induced momentum convergence and divergence also displace poleward accordingly. Similar changes in the spectra are also found in the 40-yr trend from 1960 to 2000 in the same model, which has been attributed to a combination of ozone depletion and global warming and the associated stratospheric wind anomalies (Chen and Held 2007). We are prompted to argue that increase in phase speed of the dominant eddies is a key ingredient of the poleward shift of the jet and eddy-driven overturning circulation, a notion further supported by a study using idealized atmospheric models, wherein increasing the phase speed of the up- per-tropospheric eddies can indeed shift the jet poleward (Chen et al. 2007).

While the eddy spectra analysis alone does not tell the causality between the jet shift and the increase of eddy phase speeds, the distinct eddy phase speed change under global warming versus El Niño may be indicative of different sources of their change. In the former case, the zonal winds are strengthened on the poleward flank of the climatological jet, where the eddies are generated, while the deep tropical warming in the latter case accelerates the jet's equatorward flank, where the eddies are absorbed, and thus the region of eddy absorption is modified by the subtropical wind anomalies (comparing between the solid and dashed curves in Figs. 9 and 10). This picture is further justified by an idealized model study, in which a zonal torque is introduced on either side of the climatological jet, and generates qualitatively similar jet shifts and associated 
eddy spectrum changes as seen here (Chen and ZuritaGotor 2008).

The cause of the increase of the phase speed of the midlatitude eddies remains to be explained. One probable candidate is the upper-tropospheric-lowerstratospheric wind anomalies. Increasing $\mathrm{CO}_{2}$ forcing (including the surface warming response and the feedbacks to it) cools the stratosphere and warms the troposphere (Manabe and Wetherald 1967). Because of the downward slope of the tropopause as one moves poleward, this differential heating enhances the poleward temperature gradient and the associated thermal wind near the tropopause slope. (Note that the slight stratospheric warming in the $\mathrm{SH}$ of Fig. $2 \mathrm{~b}$, owing to ozone recovery specified in the A2 scenario, is overcome by substantial tropospheric warming, and thus this simple argument still holds.) To demonstrate the connection of the $\mathrm{HC}$ expansion to the upper-level cross-tropopause meridional temperature gradient, we plot the trend in the southern boundary of the Hadley cell against the trend of the 200-hPa temperature difference (fitted to a linear slope) between $30^{\circ}$ and $55^{\circ} \mathrm{S}$ in Fig. 11. Not only does the ensemble mean (open circle) show a significant increase of temperature gradient (negative value), but a larger poleward shift of the $\mathrm{HC}$ boundary tends to occur with a larger increase in the gradient. Recent idealized baroclinic eddy life cycle experiments have shown that the increased lowerstratospheric wind (or equivalently, meridional temperature gradient) anomalies can accelerate the eastward propagation of tropospheric eddies (Wittman et al. 2007). Put together, it is conceivable that the increased temperature gradient and the associated thermal wind near the lower stratosphere and upper troposphere, a result arguably of diabatic and/or thermodynamic origin, accelerates the speed of the midlatitude jet and thus increases the phase speed of the midlatitude baroclinic eddies.

\section{c. Role of tropopause rise}

Several studies (Haigh et al. 2005; Williams 2006; Lorenz and DeWeaver 2007) have found that the tropopause rise can cause the jet to move poleward in simple dry GCMs. By manipulating the prescribed radiative equilibrium temperature of the stratosphere in these models, these authors found that warming (cooling) the stratospheric temperature at mid-high latitudes lowers (raises) the extratropical tropopause and causes the jets to move equatorward (poleward) and the HC to shrink (expand), while warming (cooling) only at the low latitudes results in opposite changes in the jet position and the HC extent. Uniform warming (cooling) of the stratosphere can also generate a signif-

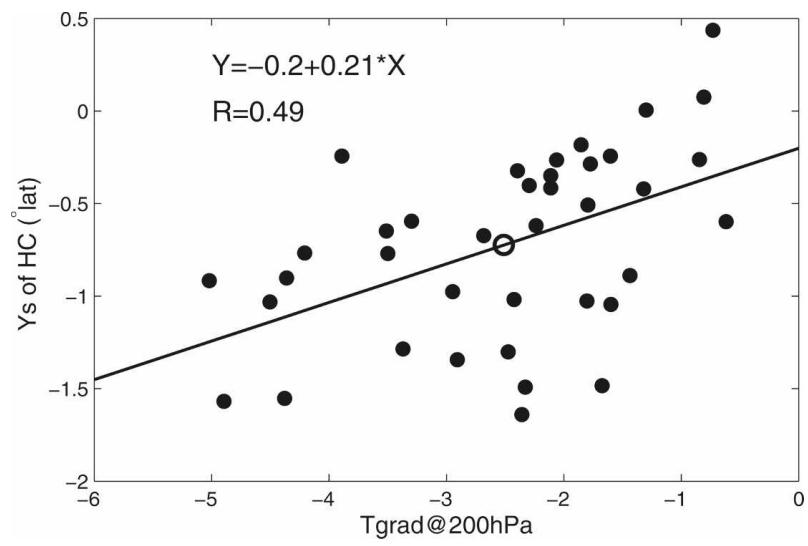

FIG. 11. Relationship between the SH expansion of the Hadley cell and $200-\mathrm{hPa}$ temperature gradient $(\mathrm{K})$ between $30^{\circ}$ and $55^{\circ} \mathrm{S}$ during DJF. The open circle denotes the ensemble mean value.

icant equatorward (poleward) shift of the jets as well. However, no feasible physical mechanism is provided in these studies. Recalling that the tropopause slopes downward from equator to pole, the uniform stratospheric cooling also introduces a poleward temperature gradient near the slope of the tropopause, accompanied by positive upper-tropospheric-lower-stratospheric wind anomalies. The increase of the phase speed (faster upper-level thermal wind leads to faster phase speed, based on simple relationship of the phase speed to the background potential vorticity gradient at the tropopause; Wittman et al. 2007) of the equatorward propagating waves and the associated interaction with the mean flow at the critical latitudes, might be the physical mechanism in action during the response to the changes of tropopause.

So far, two prominent dynamical factors-the subtropical baroclinicity and upper-tropospheric-lowertropospheric temperature gradient (or tropopause rise as a variant) - have been hypothesized to be responsible for the poleward shift of the westerly jet and the expansion of the HC under global warming. However, simple diagnostic analyses here cannot sufficiently answer the causality relationship in each mechanism and their relative contributions to these circulation changes in the global warming climate change. We believe that intelligently devised simulations either in more simplified domains or with more simplified models (e.g., Frierson et al. 2006) may be the appropriate approach to distinguish these two hypotheses.

\section{Summary and concluding remarks}

Despite the fact that a majority of the WCRP CMIP3 models produces an El Niño-like enhanced tropical Pacific warming, a weakened Walker circulation, and a 
reduction of the zonal slope of the equatorial thermocline (Vecchi et al. 2005) in responding to increased GHG forcing, we find no analogy to the El Niño teleconnection in their extratropical atmospheric response. Instead, the mid-low-level subtropical air temperature gradient decreases, the zonal mean midlatitude westerlies shift poleward, the Aleutian low weakens and the subtropical highs move poleward, and the $\mathrm{HC}$ weakens and expands poleward-all in an opposite fashion to the responses to El Niño forcing.

To contrast global warming with El Niño, only the boreal winter months are analyzed. We find that, during the DJF months in $\mathrm{SH}$, the displacements of the $\mathrm{HC}$ boundary are closely tied to the variations in the midlatitude jet, both arguably being integral parts of one three-dimensional circulation, and likely sharing the same driving mechanisms. Two hypothesized mechanisms are proposed based on analyzing the simulations of the CMIP3 data and other idealized modeling studies (Chen and Zurita-Gotor 2008; Lorenz and DeWeaver 2007; Williams 2006). A simple scaling based on Phillips' criterion for baroclinic instability demonstrates that the poleward expansion of the $\mathrm{HC}$ and the shift of the eddy-driven jet are related to the reduction of baroclinicity at the equatorward flank of the jet, which stabilizes eddy growth and pushes the eddy-driven jet and the eddy-driven subsidence toward the poles. The increased static stability, a well-established observational and model phenomenon from the quasi-moist adiabatic adjustment of the atmosphere to surface moistening in both the tropics (Xu and Emanuel 1989) and the midlatitudes (Juckes 2000; Frierson et al. 2006; Frierson 2006, 2008), seems to be a most fundamental factor in stabilizing the subtropical eddy activity, while the lowlevel meridional temperature gradient seems to play only a secondary role.

An alternative mechanism is proposed via varying the tropopause height in dry dynamical models by Lorenz and DeWeaver (2007) among others. By design, the tropospheric static stability in these model experiments remains basically intact, but the jet position and the boundary of the $\mathrm{HC}$ extent can displace significantly poleward in responding to the rise of tropopause height. This hypothesis is also corroborated by a more recent scaling analysis of the CMIP3 simulations (Lu et al. 2007). Space-time cospectral analysis of the eddy momentum fluxes reveals that the eddy-mean flow interaction near the critical latitude might be the key ingredient in the responses to tropopause change. A higher-than-normal tropopause is associated with an upper-tropospheric warming and a stratospheric cooling. Because the tropopause height declines poleward at midlatitudes, the differential heating at either sides of the tropopause increases the meridional temperature gradient, giving rise to faster thermal winds, and hence faster wave speeds. The fundamental character of the critical layer dynamics, which confines waves of faster phase speed more poleward, implies that wave spectra being shifted toward faster phase speeds should produce a poleward shift in the eddy momentum flux convergence and an associated shift in the eddy-driven jet and the eddy-driven HC subsidence.

So far, we have only focused on the responses during the boreal wintertime. The boreal summer Hadley cells and midlatitude jets show somewhat distinct features in their response to global warming. During June-August (JJA) months, the SH HC also undergoes robust poleward expansion, the extent of which is correlated to the subtropical static stability, implicative of the relevance of Held et al. (2000) scaling theory. Interestingly, the SH midlatitude jet during these months seem to be decoupled from the HC, no relationship can be identified between the shift of the jet and the expansion of the HC. In addition, there is more of a strengthening than a shift in the eddy-driven winds (see also Lorenz and DeWeaver 2007). Thus, it is possible that different mechanisms [i.e., other than the Held (2000) theory] come into play in the variations of the eddy-driven jet during $\mathrm{SH}$ winter. In the $\mathrm{NH}$ summer, there is no consensus across the models on which direction the weak subsidence of the summer cell will move, an issue we must therefore leave out of discussion.

Despite the uncertainties regarding the $\mathrm{NH}$ summer, the robustness of the expansion in the annual mean $\mathrm{HC}$ is remarkable, and it must lead to profound impacts on both the subtropical ocean and land in the warming climate. The impact on the zonal mean subtropical hydrological cycle has been briefly discussed by $\mathrm{Lu}$ et al. (2007). It has also been argued (Seager et al. 2007) that the HC expansion is partially responsible for the projected aridity and water shortage in the $\mathrm{NH}$ subtropical land areas (e.g., the American Southwest and the Mediterranean Europe). It is also compelling to examine the impacts of the expansion on the subtropical ocean circulation, and the oceanic biological and ecological system. With regard to the dynamics of the HC expansion and the poleward shift of the jet stream, questions still remain as to the role of the feedback from the spatial distribution of the SST warming (such as the accentuated warming near the extension of the Kuroshio, the temperature gradient in the extratropical Southern Oceans), and more generally, the role of dynamical interaction between the ocean and atmosphere near the subtropics and midlatitudes. All these should be fruitbearing areas of climate change research and warrant further investigations. 
Acknowledgments. First and foremost, we are grateful to Dr. Isaac Held for his mentorship and inspiring conversations on various issues of climate change and climate dynamics during our years at Princeton. We also thank Clara Deser and Jeff Yin for his helpful internal review at NCAR. The insightful comments from the two anonymous reviewers have significantly improved the clarity of the manuscript. We acknowledge the international modeling group for providing their data for analysis, the Program for Climate Model Diagnosis and Intercomparison (PCMDI) for collecting and archiving the model data, the JSC/CLIVAR Working Group on Coupled Modeling (WGCM) and their Coupled Model Intercomparison Project (CMIP) and Climate Simulation Panel for organizing the model data and analysis activity, and the IPCC WG1 TSU for technical support. The IPCC Data Archive at Lawrence Livermore National Laboratory is supported by the Office of Science, U.S. Department of Energy. J. L. is supported by the Visiting Scientist Program of the University Corporation for Atmospheric Research and the Advanced Study Program of the National Center for Atmospheric Research. D. M. W. F. is supported by a start-up grant from the University of Washington. G. C. is supported by the NOAA Climate and Global Change Postdoctoral Fellowship, administered by the University Corporation for Atmospheric Research, which is sponsored by the National Science Foundation.

\section{REFERENCES}

Allen, M. R., and W. J. Ingram, 2002: Constraints on future changes in the hydrological cycle. Nature, 419, 224-228.

Cane, M. A., A. C. Clement, A. Kaplan, Y. Kushnir, R. Murtugudde, D. Pozdnyakov, R. Seager, and S. E. Zebiak, 1997: 20th century sea surface temperature trends. Science, 275, 957-960.

Chang, E. K. M., 1995: The influence of Hadley circulation intensity changes on extratropical climate in an idealized model. $J$. Atmos. Sci., 52, 2006-2024.

Chen, G., and I. M. Held, 2007: Phase speed spectra and the recent poleward shift of Southern Hemisphere surface westerlies. Geophys. Res. Lett., 34, L21805, doi:10.1029/2007GL031200.

_ , and P. Zurita-Gotor, 2008: The tropospheric jet response to prescribed zonal forcing in an idealized atmospheric model. $J$. Atmos. Sci., 65, 2254-2271.

—, I. M. Held, and W. A. Robinson, 2007: Sensitivity to the latitude of the surface westerlies to surface friction. J. Atmos. Sci., 64, 2899-2915.

- J. Lu, and D. M. W. Frierson, 2008: Phase speed spectra and the latitude of surface westerlies: Interannual variability and global warming trend. J. Climate, 21, 5942-5959.

Clement, A. C., R. Seager, M. A. Cane, and S. E. Zebiak, 1996: An ocean dynamical thermostat. J. Climate, 9, 2190-2196.

Collins, M., and The CMIP Modeling Groups, 2005: El Niño- or La Niña-like climate change? Climate Dyn., 24, 89-104.

Delworth, T. L., and Coauthors, 2006: GFDL's CM2 global coupled climate models. Part I: Formulations and simulation characteristics. J. Climate, 19, 643-674.

Frierson, D. M. W., 2006: Robust increases in midlatitude static stability in global warming simulations. Geophys. Res. Lett., 33, L24816, doi:10.1029/2006GL027504.

_, 2008: Midlatitude static stability in simple and comprehensive general circulation models. J. Atmos. Sci., 65, 1049-1062.

_ I. Held, and P. Zurita-Gotor, 2006: A gray-radiation aquaplanet moist GCM. Part I: Static stability and eddy scale. $J$. Atmos. Sci., 63, 2548-2566.

- J. Lu, and G. Chen, 2007: The width of the Hadley cell in simple and comprehensive general circulation models. Geophys. Res. Lett., 34, L18804, doi:10.1029/2007GL031115.

Garreaud, R. D., and D. S. Battisti, 1999: Interannual (ENSO) and interdecadal (ENSO-like) variability in the Southern Hemisphere tropospheric circulation. J. Climate, 12, 2113 2123.

Griffies, S. M., M. J. Harrison, R. C. Pacanowski, and A. Rosati, 2003: A technical guide to MOM4. GFDL Ocean Group Tech. Rep. 5, NOAA/Geophysical Fluid Dynamical Laboratory, Princeton, NJ, 295 pp.

Haigh, J. D., M. Blackburn, and R. Day, 2005: The response of tropospheric circulation to perturbations in lowerstratospheric temperature. J. Climate, 18, 3672-3685.

Hansen, J., M. Sato, and R. Ruedy, 1997: Radiative forcing and climate response. J. Geophys. Res., 102 (D6), 6831-6864.

Hayashi, Y., 1971: A generalized method of resolving disturbances into progressive and retrogressive waves by space Fourier and time cross-spectral analyses. J. Meteor. Soc. Japan, 49, 125-128.

Held, I. M., and A. Y. Hou, 1980: Nonlinear axially symmetric circulations in a nearly inviscid atmosphere. J. Atmos. Res., 37, 515-533.

— , and E. O'Brien, 1992: Quasigeostrophic turbulence in a three-layer model: Effects of vertical structure in the mean shear. J. Atmos. Sci., 49, 1861-1870.

_, and B. J. Soden, 2006: Robust response of the hydrological cycle to global warming. J. Climate, 19, 5686-5699.

- and Coauthors, 2000: The general circulation of the atmosphere. Proc. 2000 Program in Geophysical Fluid Dynamics. Woods Hole, MA, Woods Hole Oceanographic Institute, 1-54. [Available online at http://gfd.whoi.edu.]

Juckes, M. N., 2000: The static stability of the midlatitude troposphere: The relevance of moisture. J. Atmos. Sci., 57, 30503057.

Kim, H., and S. Lee, 2004: The wave-zonal mean flow interaction in the Southern Hemisphere. J. Atmos. Sci., 61, 1055-1067.

Knutson, T. R., and S. Manabe, 1995: Time-mean response over the tropical Pacific to increased $\mathrm{CO}_{2}$ in a coupled oceanatmosphere model. J. Climate, 8, 2181-2199.

Kushner, P. J., I. M. Held, and T. L. Delworth, 2001: Southern Hemisphere atmospheric circulation response to global warming. J. Climate, 14, 2238-2249.

L'Heureux, M. L., and D. W. J. Thompson, 2006: Observed relationships between the El Niño-Southern Oscillation and the extratropical zonal-mean circulation. J. Climate, 19, 276-287.

Liu, Z., S. J. Vavrus, F. He, N. Wen, and Y. Zhang, 2005: Rethinking tropical ocean response to global warming: The enhanced equatorial warming. J. Climate, 18, 4684-4700.

Lorenz, D. J., and E. T. DeWeaver, 2007: The tropopause height and the zonal wind response to global warming in the IPCC scenario integrations. J. Geophys. Res., 112, D10119, doi:10.1029/2006JD008087. 
Lu, J., G. Vecchi, and T. Reichler, 2007: Expansion of the Hadley cell under global warming. Geophys. Res. Lett., 34, L06805, doi:10.1029/2006GL028443.

Manabe, S., and R. T. Wetherald, 1967: Thermal equilibrium of the atmosphere with a given distribution of relative humidity. J. Atmos. Sci., 24, 241-259.

Phillips, N. A., 1954: Energy transformations and meridional circulations associated with simple baroclinic waves in a twolevel, quasi-geostrophic model. Tellus, 6, 273-286.

Randel, W. J., and I. M. Held, 1991: Phase speed spectra of transient eddy fluxes and critical layer absorption. J. Atmos. Sci., 48, 688-697.

Reichler, T., M. Dameris, and R. Sausen, 2003: Determining the tropopause height from gridded data. Geophys. Res. Lett., 30, 2042, doi:10.1029/2003GL018240.

Robinson, W. A., 2002: On the midlatitude thermal response to tropical warming. Geophys. Res. Lett., 29, 1190, doi:10.1029/ 2001 GL014158.

Seager, R., and R. Murtugudde, 1997: Ocean dynamics, thermocline adjustment, and regulation of tropical SST. J. Climate, 10, 521-534.

—, N. Harnik, Y. Kushnir, W. Robinson, and J. Miller, 2003: Mechanisms of hemispherically symmetric climate variability. J. Climate, 16, 2960-2978.

— sition to a more arid climate in southwestern North America. Science, 316, 1181-1184.

Son, S.-W., and S. Lee, 2005: The response of westerly jets to thermal driving in a primitive equation model. J. Atmos. Sci., 62, 3741-3757.

Van Oldenborgh, G. J., S. Y. Philip, and M. Collins, 2005: El Niño in a changing climate: A multi-model study. Ocean Sci., 1, 81-95.
Vecchi, G. A., and B. J. Soden, 2007: Global warming and the weakening of the tropical circulation. J. Climate, 20, 43164340 .

- - A. T. Wittenberg, I. M. Held, A. Leetmaa, and M. J. Harrison, 2005: Weakening of tropical Pacific atmospheric circulation due to anthropogenic forcing. Nature, 441, 73-76.

Walker, C. C., and T. Schneider, 2006: Eddy influences on Hadley circulations: Simulations with an idealized GCM. J. Atmos. Sci., 63, 3333-3350.

Williams, G. P., 2006: Circulation sensitivity to tropopause height. J. Atmos. Sci., 63, 1954-1961.

Wittenberg, A. T., A. Rosati, N.-C. Lau, and J. J. Ploshay, 2006: GFDL's CM2 global coupled models. Part III: Tropical Pacific climate and ENSO. J. Climate, 19, 698-722.

Wittman, M. A. H., A. J. Charlton, and L. M. Polvani, 2007: The effect of lower stratospheric shear on baroclinic instability. $J$. Atmos. Sci., 64, 479-496.

World Meteorological Organization, 1957: Meteorology-A three-dimensional science: Second session of the commission for aerology. WMO Bull., IV, 134-138.

Xu, K., and K. A. Emanuel, 1989: Is the tropical atmosphere conditionally unstable? Mon. Wea. Rev., 117, 1471-1479.

Yamaguchi, K., and A. Noda, 2006: Global warming patterns over the North Pacific: ENSO versus AO. J. Meteor. Soc. Japan, 84, 221-241.

Yin, J. H., 2005: A consistent poleward shift of the storm tracks in simulations of 21st century climate. Geophys. Res. Lett., 32, L18701, doi:10.1029/2005GL023684.

Zhang, M., and H. Song, 2006: Evidence of deceleration of atmo spheric vertical overturning circulation over the tropical Pacific. Geophys. Res. Lett., 33, L12701, doi:10.1029/2006GL025942. 